\title{
seNorge2 daily precipitation, an observational gridded dataset over Norway from 1957 to the present day
}

\author{
Cristian Lussana ${ }^{1}$, Tuomo Saloranta ${ }^{2}$, Thomas Skaugen ${ }^{2}$, Jan Magnusson $^{2}$, Ole Einar Tveito ${ }^{1}$, and \\ Jess Andersen ${ }^{2}$ \\ ${ }^{1}$ Norwegian Meteorological Institute, Oslo, Norway \\ ${ }^{2}$ Norwegian Water Resources and Energy Directorate, Oslo, Norway \\ Correspondence: Cristian Lussana (cristianl@met.no)
}

Received: 30 June 2017 - Discussion started: 28 August 2017

Revised: 6 December 2017 - Accepted: 23 December 2017 - Published: 1 February 2018

\begin{abstract}
The conventional climate gridded datasets based on observations only are widely used in atmospheric sciences; our focus in this paper is on climate and hydrology. On the Norwegian mainland, seNorge 2 provides high-resolution fields of daily total precipitation for applications requiring long-term datasets at regional or national level, where the challenge is to simulate small-scale processes often taking place in complex terrain. The dataset constitutes a valuable meteorological input for snow and hydrological simulations; it is updated daily and presented on a high-resolution grid ( $1 \mathrm{~km}$ of grid spacing). The climate archive goes back to 1957. The spatial interpolation scheme builds upon classical methods, such as optimal interpolation and successivecorrection schemes. An original approach based on (spatial) scale-separation concepts has been implemented which uses geographical coordinates and elevation as complementary information in the interpolation. seNorge 2 daily precipitation fields represent local precipitation features at spatial scales of a few kilometers, depending on the station network density. In the surroundings of a station or in dense station areas, the predictions are quite accurate even for intense precipitation. For most of the grid points, the performances are comparable to or better than a state-of-the-art pan-European dataset (E-OBS), because of the higher effective resolution of seNorge2. However, in very data-sparse areas, such as in the mountainous region of southern Norway, seNorge2 underestimates precipitation because it does not make use of enough geographical information to compensate for the lack of observations. The evaluation of seNorge 2 as the meteorological forcing for the seNorge snow model and the DDD (Distance Distribution Dynamics) rainfall-runoff model shows that both models have been able to make profitable use of seNorge2, partly because of the automatic calibration procedure they incorporate for precipitation. The seNorge2 dataset 1957-2015 is available at https://doi.org/10.5281/zenodo.845733. Daily updates from 2015 onwards are available at http://thredds.met.no/thredds/catalog/metusers/senorge2/seNorge2/ provisional_archive/PREC1d/gridded_dataset/catalog.html.
\end{abstract}

\section{Introduction}

Conventional climatological datasets are based on observed data only and they provide valuable information for a large spectrum of users in modern societies (Simmons et al., 2016). The Norwegian Meteorological Institute (MET) produces and maintains the seNorge collection of high-resolution gridded datasets for daily mean temperature and total precipitation in support of climate, hydrology and atmospheric sciences in general.
The object of this paper is the daily total precipitation gridded fields of the latest seNorge version 2.0 (or simply seNorge 2). It is worth mentioning that the seNorge2 daily mean temperature dataset has been described in the paper by Lussana et al. (2018). Despite being released only recently, seNorge 2 has already been used in a few applications, such as snow and permafrost mapping (Gisnås et al., 2017) and evaluation of climate projections (Kotlarski et al., 2017). Most noticeably, the Norwegian Water Resources and Energy Di- 
rectorate (NVE) uses seNorge2 as meteorological forcing for the national forecasting system for floods, avalanches and landslides. As a consequence, the temperature and precipitation fields are regularly updated on a daily basis.

The daily precipitation dataset has a focus on the Norwegian mainland, though it extends into Sweden and Finland too, and it is produced on a regular grid with $1 \mathrm{~km}$ grid spacing in both the Easting and Northing directions. The data are presented as (i) an historical archive covering the period from 1957 to 2015 , which is available at http://doi.org/10.5281/zenodo.845733; (ii) daily updates from 2015 onwards, available for public download at http://thredds.met.no/thredds/catalog/metusers/senorge2/ seNorge2/provisional_archive/PREC1d/gridded_dataset/ catalog.html. The current historical archive has been named "release 17.08", with reference to the release date August 2017. MET is planning to make available regular updated releases of this dataset to the users. The file format chosen is the Network Common Data Form (netCDF) and the files include numerous descriptive attributes.

The seNorge 2 statistical interpolation method is based on a modified optimal interpolation (OI: Eliassen, 1954; Gandin and Hardin, 1965) scheme, where innovative ideas on the interaction between precipitation at different spatial scales have been implemented. OI has been developed as an objective analysis scheme for meteorological fields, and then it has been widely used in data assimilation to provide initial conditions for numerical models (Kalnay, 2003; Daley, 1991; Lorenc, 1986). The availability of a background or first-guess field is a central component of OI. The concept of a firstguess field was introduced in the context of objective analysis during the 1950s (Bergthörsson and Döös, 1955; Thompson, 1961) and it coincided with the prior information used in Bayesian statistical schemes. In our work, OI has been used as a spatial interpolation technique and the background field has been estimated from the in situ observations instead of being observation-independent information derived from numerical atmospheric models or climatology, as for the "classical" OI. Bayesian spatial interpolation schemes have been applied to precipitation in the past (Todini, 2001; Schiemann et al., 2010b; Lussana et al., 2009; Aalto et al., 2016). However, the absence of an independent background motivated us to adopt an approach inspired by the successivecorrection methods (Barnes, 1964) in the form proposed by Bratseth (1986). The spatial interpolation scheme developed for seNorge2 is based on an iteration of a statistical interpolation scheme over a decreasing sequence of spatial scales. This idea has been widely used for mesoscale meteorological analysis in successive-correction methods; see Uboldi and Buzzi (1994), and references therein. However, we have adapted this method to the special statistical properties of precipitation fields, and its implementation can be regarded as an original contribution to this research field.

In the scientific literature, numerous approaches have been described to address spatial interpolation of precipitation for different combinations of spatial and temporal resolutions. In the article by Hofstra et al. (2008), a review and inter-comparison of six interpolation methods can be found. Not surprisingly, a number of inter-comparison studies have found "inhomogeneities in the gridded data that are primarily caused by inhomogeneities in the underlying station data" (Hofstra et al., 2008, 2010). Haylock et al. (2008) describes a three-step process interpolation technique, aimed at establishing E-OBS: a pan-European archive of observational gridded datasets at monthly and daily timescales, available on a $0.25^{\circ}$ by $0.25^{\circ}$ latitude-longitude grid. First, monthly totals are interpolated using thin-plate splines (Wahba and Wendelberger, 1980). Second, daily values are obtained using Kriging Wackernagel (2013) and taking into account the monthly totals. The third step aims at obtaining uncertainty estimates for E-OBS. In this paper, we will use E-OBS as a reference dataset to evaluate seNorge2. The conclusions of the work by Masson and Frei (2014) favor the use of statistical interpolation schemes based on a two-step approach, where the background is estimated from the data, such as Kriging with external drift that is rather similar to OI. In addition, they conclude that the inclusion of a single topographic predictor may be sufficient in the interpolation, and they support "the common practice of using a climatological mean field as a background in the interpolation of daily precipitation". OI combined with principal component analysis have been used to reconstruct historical climate datasets of precipitation in Switzerland (Schiemann et al., 2010b). In the paper by Crespi et al. (2016), an interpolation approach based on local weighted linear regression (LWLR) has been compared with local regression Kriging (RK). This last method (RK) uses only geographical coordinates and elevation, while LWLR uses several additional geographical parameters, such as slope steepness, slope orientation and distance from the sea. LWLR shows better results than RK at high-elevation sites provided that the data density is sufficiently high, while "RK is more robust in performing extrapolation over areas with complex orography and scarce data coverage, where LWLR may provide unrealistic precipitation values", thus indicating that the inclusion of additional geographical information in complex terrain can actually improve the interpolation results, though once again the results of a method over a specific domain strongly depend on the station network available. The paper by Masson and Frei (2016) contains important remarks and recommendations on the use of gridded datasets for computing temporal trends of precipitation, which is not at all straightforward because of "artifacts in trend patterns due to local inhomogeneities in the data and the station network".

The previous seNorge versions (v1.0 and v1.1) were based on a linear estimation of precipitation on the grid (Førland and Tveito, 1997; Mohr, 2008, 2009): for each point, the three closest observations are identified by means of a triangulation procedure, and then the (linear) estimated value is adjusted taking into account both the elevation differences 
and the geographical characteristics of the site surrounding the grid point that may cause undercatch of precipitation due to the effect of wind (i.e., "wind field deformation and deflection of hydrometeors over the gauge orifice results in a systematic measurement bias" - Frei et al., 2003).

seNorge 2 uses the information from much more than the three closest stations to estimate precipitation in a location; in addition, geographical information such as elevation, latitude and longitude has been incorporated into the statistical interpolation scheme.

seNorge 2 has been evaluated by means of several complementary approaches, such as analysis of a case study; accumulation over a temporal period much longer than 1 day; verification of the performances at station locations by using summary statistics and skill scores; and verification of the performances over grid points by comparing seNorge2 to E-OBS, which was recently chosen by the Copernicus Climate Change Service as a reference dataset for Europe (https://insitu.copernicus.eu/news/ the-european-climate-assessment-dataset-and-copernicus).

Because of the importance of seNorge 2 as input for hydrological applications, the indirect evaluation of the precipitation fields as components of the water cycle by means of snow and hydrological models has been included in the paper. Indirect evaluation relies on the fact that successful modeling of hydrological processes requires reliable meteorological forcing data, which is a crucial but often undervalued element of the model chain (e.g., Magnusson et al., 2015). Indirect evaluation has proven useful in the verification of surface models (Masson et al., 2013), for example. Our approach is similar to the one described by Berg et al. (2014) to evaluate long-term precipitation.

The outline of the paper is as follows. Section 2 presents the geographical area and the observations used. In Sect. 3 the seNorge2 statistical interpolation method is described. The evaluations of the precipitation fields at station locations and over the grid points are reported in Sect. 4. The indirect evaluation of precipitation as a component of the water cycle is reported in Sect. 5, together with brief descriptions of the seNorge snow model and the DDD (Distance Distribution Dynamics) rainfall-runoff model that have been used for the indirect evaluation.

\section{Geographical area and data}

The seNorge2 domain is shown in Fig. 1. The geographical area of interest is the Norwegian mainland, plus a strip of land extending into Sweden and Finland that has been added so as to properly cover the Norwegian catchments stretching along the national borders. The domain is characterized by a complex topography, with the highest peaks above $2000 \mathrm{~m}$ in southern Norway and in northern Sweden. The steep topography is known to cause pronounced orographic enhance-

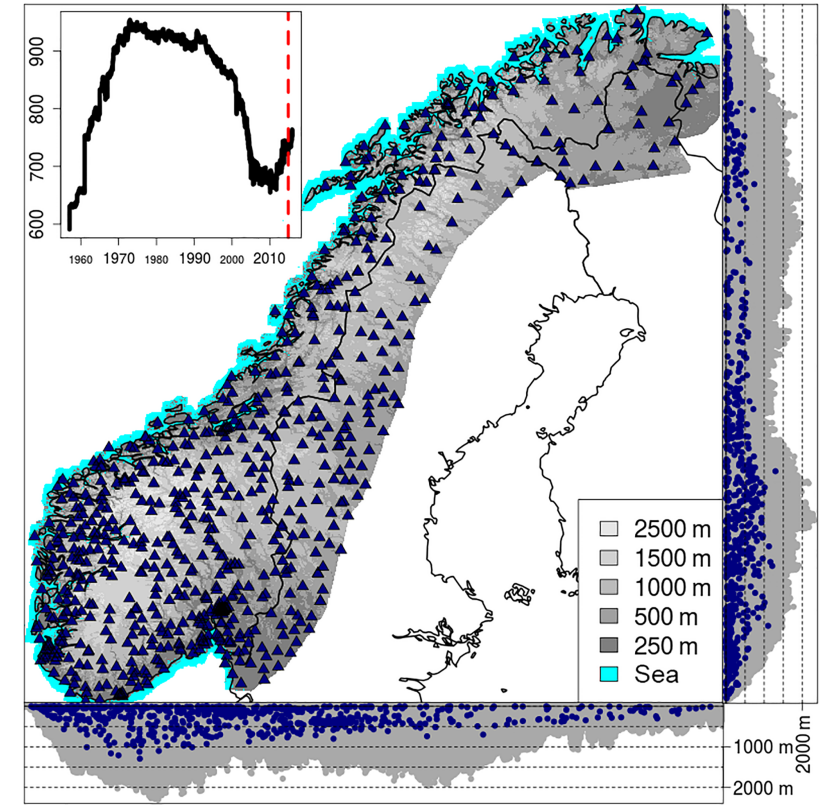

Figure 1. seNorge2 domain, topography (gray shades, meters above mean sea level) and station locations (blue triangles, valid for the date: 24 November 2014). The total number of station locations in the example is 737 . The top-left inset shows the time series for the number of available observations for the whole period covered by the dataset: 1957-2015; the red line marks the day 24 November 2014. The two lateral panels show the distributions of elevations for both the digital elevation model (gray dots) and stations (blue dots) along the Easting (bottom panels) and Northing (lateral panel) coordinates.

ment of precipitation along the Norwegian coast, especially along the western coast of southern Norway.

The daily precipitation for day $D$ has been defined as the accumulated precipitation between 06:00 UTC of day $D-1$ and 06:00 UTC of day $D$. The dataset is based on in situ observations from the Norwegian Climate Database (data.met.no). We also include data from the European Climate Assessment Dataset (ECA\&D: Klein Tank et al., 2002) for regions neighboring Norway. The original nonhomogenized time series have been used, to have a larger dataset than the one provided by the homogenized time series. The number of stations used for the interpolation varies with time due to data availability and the station distribution is uneven throughout the spatial domain. As an example, in Fig. 1 the spatial distribution of stations for 24 November 2014 is shown, together with the time series of the number of available observations for the whole period covered by the dataset. In the case of 24 November 2014, which is close to the end of the period covered by the historical dataset, 737 observations were available. The number of observations vary between 600, before 1960, and approximately 900 during the seventies and the nineties, and then the number of observations gradually decrease to approximately 700 before 
increasing again after 2010. In general, the station network is denser in the southern part of the domain, while it becomes sparser in its northernmost part. With reference to the hierarchy of atmospheric motions proposed by Thunis and Bornstein (1996), the average distances between nearby station locations correspond to the lower boundary of the mesoscale (meso- $\gamma$ ), and they are consistent with the representation of thunderstorms, thunderstorm groups and fronts. The two panels in Fig. 1 show the distribution of station elevations together with the domain topography; the stations are located at elevations that seldom exceed $1000 \mathrm{~m}$, so that it might be expected that predicted precipitation fields would be more representative and accurate for lower elevations than in the highest mountains.

\section{Methods}

\subsection{Optimal interpolation}

The OI aims at providing the best (i.e., minimum error variance for the analysis), linear, unbiased estimate of the unknown meteorological field by combining prior information (i.e., background) on the grid with in situ observations. In the following, we use the same notation as Lussana et al. (2010) (based on Ide et al., 1997): the vector $\boldsymbol{y}$ indicates the $m$ observations of either air temperature or precipitation, and the vector $\boldsymbol{x}$ represents the $n$ grid cells. Superscripts o, b and a denote observation, background and analysis, respectively, while the superscript $t$ indicates the unknown true value. Matrices are in bold roman type (capital letters). Scalar variables are in italic type, so the $i$ th component of a vector $\boldsymbol{x}$ is $x_{i}$, while for a generic matrix $\mathbf{W}$, components are indicated as $W_{i j}$.

OI relies on the assumptions of Gaussian distribution for both the observation error $\boldsymbol{\varepsilon}^{\mathrm{o}} \equiv \boldsymbol{y}^{\mathrm{o}}-\boldsymbol{y}^{\mathrm{t}}$ and the background error $\boldsymbol{\varepsilon}^{\mathrm{b}} \equiv \boldsymbol{y}^{\mathrm{b}}-\boldsymbol{y}^{\mathrm{t}}$ (or $\boldsymbol{\eta}^{\mathrm{b}} \equiv \boldsymbol{x}^{\mathrm{b}}-\boldsymbol{x}^{\mathrm{t}}$ for grid points). As a consequence, their distributions are completely defined by their mean values and covariance matrices only. Both the observations and the background are assumed to be unbiased estimates of the true value and their error covariance matrices are specified by means of analytical functions, such that $\boldsymbol{\varepsilon}^{\mathrm{o}} \sim N(\mathbf{0}, \mathbf{R}), \boldsymbol{\varepsilon}^{\mathrm{b}} \sim N(\mathbf{0}, \mathbf{S})$ and $\eta^{\mathrm{b}} \sim N(\mathbf{0}, \mathbf{B})$. Furthermore, observations and background are regarded as uncorrelated variables.

The analysis is also a random variable with a Gaussian distribution (Jazwinski, 2007) and its mean values on the grid and at station locations can be written as

$\boldsymbol{x}^{\mathrm{a}}=\boldsymbol{x}^{\mathrm{b}}+\mathbf{K}\left(\boldsymbol{y}^{\mathrm{o}}-\boldsymbol{y}^{\mathrm{b}}\right)$,

$y^{\mathrm{a}}=\boldsymbol{y}^{\mathrm{b}}+\mathrm{W}\left(\boldsymbol{y}^{\mathrm{o}}-\boldsymbol{y}^{\mathrm{b}}\right)$,

where the two matrices of interpolation weights are $\mathbf{K}$, the gain matrix, and $\mathbf{W}$, the influence matrix.

The equations for the weight matrices $\mathbf{K}$ and $\mathbf{W}$ depend on our choices for the error covariance matrices. The observa- tion error covariance matrix $\mathbf{R}$ is assumed to be diagonal and all the observations are assumed to have the same error variance $\sigma_{\mathrm{o}}^{2}$; then, $\mathbf{R} \equiv \sigma_{\mathrm{o}}^{2} \mathbf{I}$ (I is the identity matrix). The background error covariance matrices requires the specification of the correlation between two generic points $\boldsymbol{r}_{i}=\left(x_{i}, y_{i}, z_{i}\right)$ and $\boldsymbol{r}_{j}=\left(x_{j}, y_{j}, z_{j}\right)$, which for us is the correlation function $\rho$ :

$\rho\left(\boldsymbol{r}_{i}, \boldsymbol{r}_{j}\right)=\exp \left\{-\frac{1}{2}\left[\left(\frac{d\left(\boldsymbol{r}_{i}, \boldsymbol{r}_{j}\right)}{D^{h}}\right)^{2}+\left(\frac{\Delta z\left(\boldsymbol{r}_{i}, \boldsymbol{r}_{j}\right)}{D^{z}}\right)^{2}\right]\right\}$,

where $d\left(\boldsymbol{r}_{i}, \boldsymbol{r}_{j}\right)$ is the horizontal distance between the two points; $\Delta z\left(\boldsymbol{r}_{i}, \boldsymbol{r}_{j}\right)$ is the difference between their elevations; $D^{h}$ and $D^{z}$ are the horizontal and vertical de-correlation lengths, respectively. The generic component $S_{i j}$ of the background error covariance matrix at station locations (a similar expression holds for $\mathbf{B}$ too) is $\mathrm{S}_{i j} \equiv \sigma_{\mathrm{b}}^{2} \rho\left(\boldsymbol{r}_{i}, \boldsymbol{r}_{j}\right)$, where $\boldsymbol{r}_{i}$ and $\boldsymbol{r}_{j}$ indicate the locations of the $i$ th and $j$ th stations, and the background error variance $\sigma_{\mathrm{b}}^{2}$ is assumed to be the same for all the points. The components of the background error correlation matrix at station locations $\widetilde{\mathbf{S}}$ can be written as $\widetilde{\mathrm{S}}_{i j} \equiv \rho\left(\boldsymbol{r}_{i}, \boldsymbol{r}_{j}\right)$, while the background error correlation matrix between grid points and station locations is the $n \times m$ matrix with components $\widetilde{\mathrm{G}}_{i j} \equiv \rho\left(\boldsymbol{r}_{i}, \boldsymbol{r}_{j}\right)$, where $\boldsymbol{r}_{i}$ indicates the spatial location of the $i$ th grid point and $\boldsymbol{r}_{j}$ is the $j$ th station location.

Given our assumptions about the error covariance matrices, the expressions for the weight matrices are derived directly from the theory of linear Kalman filters (Uboldi et al., 2008):

$\mathbf{K}=\widetilde{\mathbf{G}}\left(\widetilde{\mathbf{S}}+\varepsilon^{2} \mathbf{I}\right)^{-1}$,
$\mathbf{W}=\widetilde{\mathbf{S}}\left(\widetilde{\mathbf{S}}+\varepsilon^{2} \mathbf{I}\right)^{-1}$,

where $\varepsilon^{2}$ is the ratio $\sigma_{\mathrm{o}}^{2} / \sigma_{\mathrm{b}}^{2}$.

Two elements of the OI diagnostics are introduced in this paragraph, because they have been used in the optimization of parameters (Sect. 3.2.2). First, the integrated data influence (IDI: Uboldi et al., 2008; Lussana et al., 2016) is the sensitivity of the analysis in a generic point on the domain to variations in the observations, independently of the actual observed values. In practice, the IDI field is the result of an OI scheme where the observations are set to 1 and the background is set to 0 , such that regions where the observations effectively introduce information have IDI values close to 1 . On the other hand, for data-void regions the IDI values are close to 0 .

Second, the leave-one-out cross-validation (CV) analysis $\check{\boldsymbol{y}}^{\mathrm{a}}$ : each component of the $m$-vector $\check{\boldsymbol{y}}^{\mathrm{a}}$ is the analysis value obtained for the corresponding station location by using all the other observations, but without using the observation measured at that station location. The equation for $\check{\boldsymbol{y}}^{\mathrm{a}}$ can be written as (Uboldi et al., 2008; Lussana et al., 2010)

$\check{\boldsymbol{y}}^{\mathrm{a}}=\boldsymbol{y}^{\mathrm{o}}+\boldsymbol{w}^{T}\left(\boldsymbol{y}^{\mathrm{a}}-\boldsymbol{y}^{\mathrm{o}}\right)$, 
where the vector $\boldsymbol{w}$ has components $w_{i}=\left(1-W_{i i}\right)^{-1}$. The deviation between the $\mathrm{CV}$ analysis and its corresponding observation represents an estimate of the analysis error based on the idea that each observation is used as an independent verification of the analysis field. Because not all the available information is used, the error estimate can be regarded as a conservative one.

\subsection{Spatial interpolation of daily accumulated precipitation}

The precipitation field is regarded as a composition of several (precipitation) events, which are considered individually, in the sense that the statistical properties of the field are allowed to change between events.

For each event, the statistical interpolation scheme has been implemented by means of an iterative algorithm on a cascade of spatial scales, ranging from the synoptic scale down to the small scale. As stated in Uboldi et al. (2008), given the filtering properties of OI, the choice of the scale parameters $D^{h}$ and $D^{z}$ in the correlation function $\rho$ (Eq. 3) determines a minimum distance scale (wavelength) resolved by the analysis. In addition, the spatial resolution of the observational network dictates a minimum for that choice because those small spatial features not resolved by the observational network will not be accurately represented by the analysis. The iterative algorithm presented exploits the OI filtering properties. Starting from a first-guess of the average precipitation value (i.e., the largest scale), several successive iterations of OI-derived corrections (over a decreasing sequence of values for $D^{h}$ ) are applied to the predicted precipitation field.

\subsubsection{Identification of events}

An individual event on the grid is a connected zone of grid points where the precipitation exceeds the predefined threshold of 0.1 mm day $^{-1}$.

Initially, a first guess for the distribution of events both on the grid and for station locations is obtained. The observations measuring precipitation (i.e., wet observations) are tentatively grouped in events by using a triangulation-based procedure: two wet observations are assigned to the same event if a direct connection between them exists (i.e., they lie on the vertices of the same triangle) or if they are connected through only one observation not measuring precipitation (i.e., vertices of adjacent triangles). In this latter case, the observation not measuring precipitation (i.e., dry observation) is also included in the first guess of that event. Then, an interpolation procedure based on the nearest neighbor is used to group grid points into events. The precipitation is set to $0 \mathrm{~mm}$ for all the grid points outside the event areas.

In the second step, each event is considered individually, aiming at determining those grid points where precipitation is most likely to occur. The question is to decide whether the analysis at a grid point is more influenced by the surrounding wet observations or by the dry ones. As described in Sect. 3.1, the influence on the analysis of a set of observations can be quantified through the IDI value. Suppose that the $i$ th grid point has been assigned in our first guess to a specific event: then precipitation is most likely to occur there if the IDI of the wet observations $\left(\boldsymbol{x}^{\mathrm{IDI} w}\right)$ included in the event under consideration is greater than or equal to a fraction of the IDI of the dry observations $\left(x^{\mathrm{IDI} d}\right)$ :

$x_{i}^{\mathrm{IDI} w} \geq 0.6 \cdot x_{i}^{\mathrm{IDI} d} \rightarrow$ precipitation occurs at the $i$ th grid point.

We require that the influence of the dry observations $x_{i}^{\mathrm{IDI} d}$ must be considerably larger than $x_{i}^{\mathrm{IDI} w}$ for a grid point to be considered "dry". This can be regarded as a conservative choice; in case of uncertainty (i.e., when $x_{i}^{\mathrm{IDI} d}$ and $x_{i}^{\mathrm{IDI} w}$ are not too different), we prefer to estimate a precipitation value for the $i$ th grid point instead of taking the more drastic decision of setting it to 0 . The factor 0.6 in Eq. (7) has been set as in (Lussana et al., 2009), because it improves the agreement between the model results and the observations. As described in Sect. 3.1, the IDI values are obtained as the analysis values (Eq. 2) with the background set to 0 and the observed values set to 1 . In this case, the OI parameters used in the IDI elaboration can vary from grid point to grid point: $D^{h}$ is the horizontal distance to the closest available station location (irrespective of the observed value); $D^{z}$ is the maximum elevation within the event first-guess (a minimum value of $500 \mathrm{~m}$ is pre-set); $\varepsilon^{2} \equiv \sigma_{\mathrm{o}}^{2} / \sigma_{\mathrm{b}}^{2}=0.1$, which means that we impose the IDI field to fit the value 1 in the surroundings of observation locations.

Finally, adjacent (connected) grid points where the precipitation is most likely to occur are assigned to the same event and the event gets a unique label. The wet observations are assigned to the same event of the surrounding grid points. In the special case of a wet observation surrounded by dry grid points only, a new event is created. The isolated wet observation is associated with this new event, together with the closest grid points. This special situation may occur in dense station areas (i.e., station density comparable to the grid resolution) when, for example, only one station measures precipitation.

\subsubsection{Iterative optimal interpolation}

As stated in Sect. 3, the iterative algorithm operates on a cascade of spatial scales, which is defined through a decreasing sequence of $K$ values for $D^{h}=$ \{large scale, ..., local scale $\}$. The largest scale $D_{1}^{h}$ is set to the semi-major axis of the ellipsoid of minimal area enclosing all grid points of the event under consideration (i.e., its ellipsoid hull), and then $D_{k+1}^{h}=D_{k}^{h}-10 \mathrm{~km}(k=1, \ldots, K)$ and the local scale $D_{K}^{h}$ are set to the minimum distance between two stations (the minimum allowed value is $10 \mathrm{~km}$ ). 
The regional topography influences the precipitation patterns, and consequently points at the same elevation tend to be more correlated than points at different elevations. Because of that, we have decided to include elevation differences in our (de)correlation functions $\rho$ (Eq. 3). The sequence of $K$ vertical scales $D_{k}^{z}$ is not predefined, such as for $D^{h}$. On the contrary, they are optimized every time step and for each $D_{k}^{h}$ value. The optimal $D_{k}^{z}$ is chosen among four possible values $D^{z}=\{5000 \mathrm{~m}, 2000 \mathrm{~m}, 1000 \mathrm{~m}, 500 \mathrm{~m}\}$. A value of $D^{z}=5000 \mathrm{~m}$ means that the de-correlation of precipitation along the vertical is actually not needed; then, the de-correlation gradually increases with decreasing $D^{z}$. By decreasing the correlation $\rho$ between points, we also reduce the spatial extent of the area of influence that every observation has on the analysis. Because our method is based only on observations, a predefined lower limit of $500 \mathrm{~m}$ has been set for $D^{z}$; otherwise, the total extension of data-sparse areas may become too large.

The application of the OI iterative scheme requires the definition of two further elements: (1) a spatial averaging operator $\langle\ldots\rangle_{h, v}$ to process the vector-observed values. The operator is applied to its components to obtain for each station location a "processed observation" meant to represent the average precipitation in a neighborhood of a predefined size around that location. The neighborhood considered is a cylinder of radius $h$ and height $v$, having its center of mass at the station location; (2) $\varepsilon^{2}$ (Eqs. 4-5), the ratio between the observation and background error covariances $\varepsilon^{2}$, specifies the weight of the new information (i.e., the processed observations) compared to the background. At each iteration, the background is the result of previous iteration steps, and it represents the integrated effect of the larger spatial scales. $\varepsilon^{2}$ is set to 0.1 , as in the IDI calculation of Sect. 3.2.1, and its value is kept constant in the elaboration.

The iterative OI algorithm is based on two nested loops.

- The outer loop over the $D^{h}=\{$ large scale,..., local scale $\}$ scales (index $k=1, \ldots, K)$. For the $k$ iteration, the background is the analysis obtained at iteration $k-1: \boldsymbol{x}_{k}^{\mathrm{b}}=\boldsymbol{x}_{k-1}^{\mathrm{a}}$ and $\boldsymbol{y}_{k}^{\mathrm{b}}=\boldsymbol{y}_{k-1}^{\mathrm{a}}$. As initial conditions, the vectors $\boldsymbol{x}_{1}^{\mathrm{b}}$ and $\boldsymbol{y}_{1}^{\mathrm{b}}$ are set to the mode of the distribution of observed precipitation values.

- The inner loop over $D^{z}=\{5000 \mathrm{~m}, 2000 \mathrm{~m}$, $1000 \mathrm{~m}, 500 \mathrm{~m}\}$ (index $c=1, \ldots, 4$ ). The observation vector used is the processed observation $\boldsymbol{y}_{k, c}^{\mathrm{o}} \equiv\left\langle\boldsymbol{y}^{\mathrm{o}}\right\rangle_{D_{k}^{h}, D_{c}^{z}}$. First, the cross-validation analysis $\check{\boldsymbol{y}}_{k, c}^{\mathrm{a}}$ is computed as in Eq. (6), where the influence matrix $\mathbf{W}$ is computed using the pair $\left(D_{k}^{h}, D_{c}^{z}\right)$ in Eq. (3) to define the correlation function. Then, the optimal value for $D^{z}\left(\widetilde{D}^{z}\right)$ is chosen as the one that minimizes the relative error between $\check{\boldsymbol{y}}_{k, c}^{\mathrm{a}}$ and $\boldsymbol{y}_{k, c}^{\mathrm{o}}$ (i.e., relative error $=$ prediction/observation). However, we are not using the actual (CV) predicted and (processed) observed values in the definition of relative error. In fact, the "started logs" (st.log) (Erdin, 2009; Rocke and Durbin, 2003) of those values have been used, so as "to ensure an equal scaling of positive and negative deviations of prediction from observations and because the relative error is highly sensitive to small observations that might be under or overestimated by a large factor in the prediction" (Erdin, 2009). The relative error is written as

$$
\begin{aligned}
& \operatorname{rels}_{k, c} \\
& =\sqrt{\frac{1}{m} \cdot \sum_{j=1}^{m}\left[\operatorname{st} \log \left(\check{y}_{j, k, c}^{\mathrm{a}}\right)-\mathrm{st} \cdot \log \left(y_{j, k, c}^{\mathrm{o}}\right)\right]^{2}},
\end{aligned}
$$

where $\ldots j, k, c$ indicates the $j$ th vector component for iteration $(k, c)$ and the started logs are defined as

$$
\begin{aligned}
& \text { st. } \log (x) \\
& \quad= \begin{cases}\log _{10}(x) & \text { if } x>l_{c}, \\
\log _{10}\left(l_{c}\right)+\left(x-l_{c}\right) /\left[l_{c} \cdot \ln (10)\right] & \text { if } x \leq l_{c} .\end{cases}
\end{aligned}
$$

The critical threshold has been set to $l_{c} \equiv 1.5 \mathrm{~mm}$.

- Out of the inner loop and back to the outer loop. The analyses $\boldsymbol{x}_{k}^{\mathrm{a}}$ (Eq. 1) and $\boldsymbol{y}_{k}^{\mathrm{a}}$ (Eq. 2) are obtained; the weight matrices $\mathbf{K}$ and $\mathbf{W}$ (Eqs. 4-5) used in the analysis procedure are computed with the correlation function $\rho$ (Eq. 3) defined by the two parameters $D^{h}$ and $\widetilde{D}^{z}$.

The final analyses are $\boldsymbol{x}^{\mathrm{a}}=\boldsymbol{x}_{K}^{\mathrm{a}}$ and $\boldsymbol{y}^{\mathrm{a}}=\boldsymbol{y}_{K}^{\mathrm{a}}$.

\section{Evaluation of the precipitation fields}

\subsection{Case studies}

In Fig. 2, two examples of precipitation fields are shown. In the top panel, a case study for daily precipitation is presented, which has been chosen because it is representative of a typical situation where intense precipitation occurs. The presence of a low-pressure system over southern Norway causes the advection of moist air from over the ocean towards the mainland, thus determining intense precipitation along the coast, especially in the presence of steep topography (see Fig. 1). The figure also gives an idea of the range of spatial scales involved in such a precipitation event. In this case, the most intense part of the precipitation takes place in the south, over an area of about $500 \mathrm{~km}$ by $500 \mathrm{~km}$; inside this region, precipitation hotspots of different sizes are present, with the most intense ones (red colors) having an extension of no more than $50 \mathrm{~km}$ by $50 \mathrm{~km}$ and often far less than that. The higher the station density, the finer would be the effective spatial resolution (i.e., spatial detail) of the final prediction. In the bottom 
panel, the seNorge 2 mean annual accumulated precipitation field for the 30-year period 1981-2010 is shown. The precipitation patterns agree quite well with the expected climatology (e.g., Tveito et al., 1997). The highest precipitation amounts of more than $3000 \mathrm{~mm}$ are recorded along the western coast in southern Norway. The regions with the lowest annual precipitation amounts are recorded inland in the north and on the leeward side of the highest Norwegian mountains in the south.

\subsection{Verification at station locations}

Figure 3 shows the equitable threat score (ETS: Jolliffe and Stephenson, 2003), which "measures the fraction of observed events that were correctly predicted, adjusted for hits associated with random chance" (see the WWRP/WGNE Joint Working Group on Forecast Verification Research website at http://www.cawcr.gov.au/projects/ verification). Three gridded datasets of daily precipitation have been considered: (i) seNorge2; (ii) E-OBS (described in the introduction; version 16.0 has been used); and (iii) seNorge 2 upscaled onto the E-OBS coarser grid of about $20 \mathrm{~km}$ by $20 \mathrm{~km}$ (i.e., $0.25^{\circ}$ by $0.25^{\circ}$ regular latitudelongitude grid), so as to allow for a comparison between E-OBS and seNorge2 performances when both datasets have a similar representativeness (i.e., represents same spatial scales). Because a grid point value represents area mean conditions across (at least) one grid box, the upscaling has been done by averaging all the seNorge 2 grid points within the coarser E-OBS boxes (as recommended by Christoph Frei and Phil D. Jones; see the Appendix of the UERRA report http://uerra.eu/component/dpattachments/ ?task=attachment.download\&id=42). The ETS has been computed by taking into account all the available Norwegian data in the period 1981-2010 (i.e., approximately 5000000 observations) and the values extracted from the precipitation datasets have been evaluated against the observations. By taking into account a 30 -year period, the dataset should include enough extreme precipitation events, such that the statistics of those rare events can be considered meaningful. Note that the observations have been used in the spatial interpolation, so they do not constitute independent information, and for this reason such an evaluation provides information only for the performance at station locations and not over grid points.

seNorge 2 considered at its original resolution clearly shows the benefits of a finer effective resolution, if compared to E-OBS, especially for intense precipitation. The ETS is generally above 0.9 , and even for precipitation amounts higher than $128 \mathrm{mmday}^{-1}$ the fraction of observed events that were correctly predicted is approximately 0.8 . The best performances are obtained for daily precipitation amounts around $10 \mathrm{mmday}^{-1}$, probably because such intensities are often (i.e., more frequently than for the other intensities) related to large-scale precipitation and the uncertainties associ-
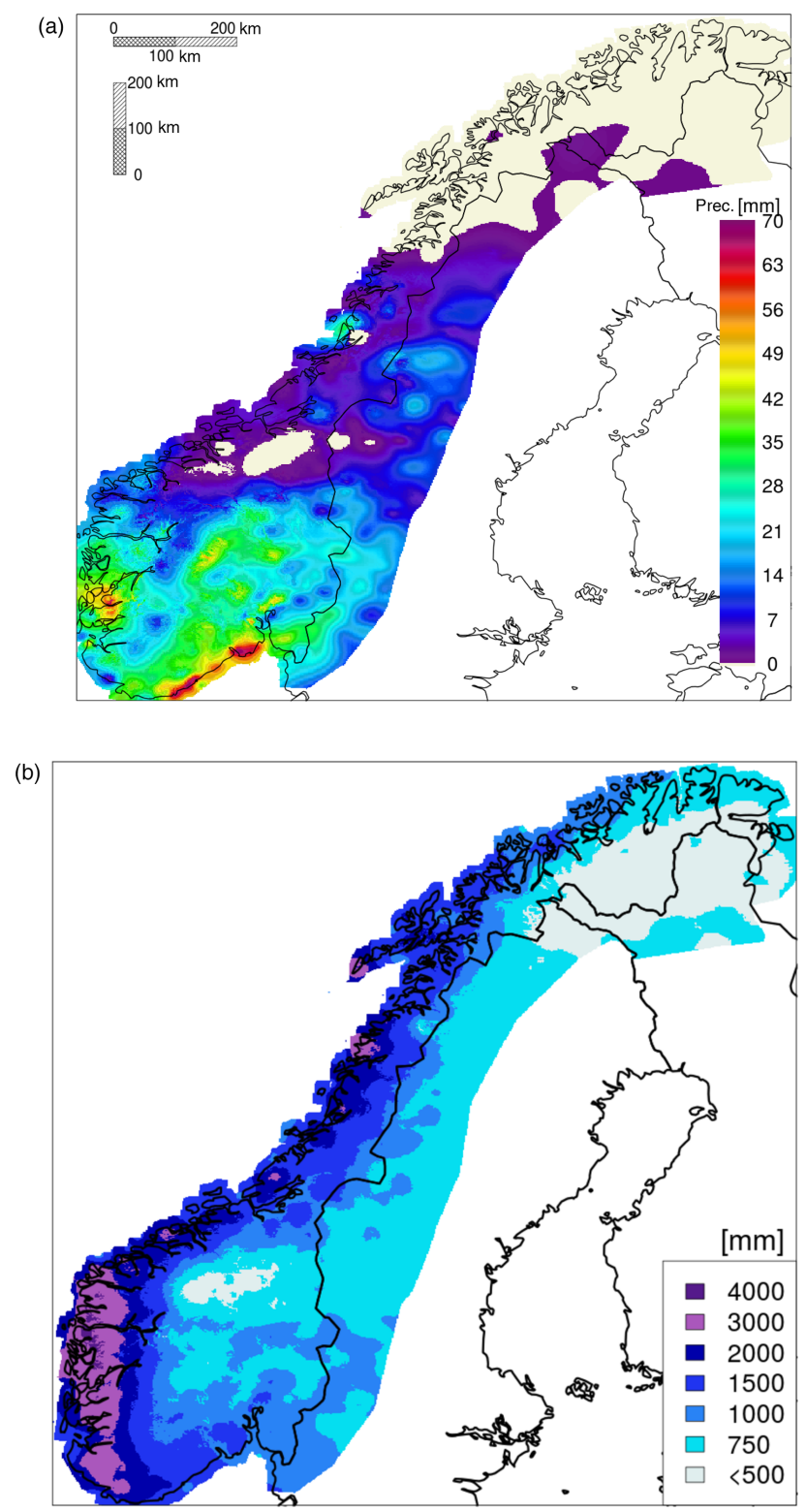

Figure 2. seNorge 2 examples. (a) Total precipitation for the day 24 November 2014. (b) Mean annual precipitation, based on the annual precipitation from 1981 to 2010 .

ated with intermittency are less significant. The comparison of seNorge 2 and E-OBS over the same (coarser) grid shows that the two datasets perform rather similarly. seNorge 2 has higher ETS values than E-OBS for most of the thresholds, though E-OBS presents slightly better ETS for the most intense precipitation amounts.

\subsection{Verification over grid points}

The quality assessment of seNorge 2 precipitation fields over grid points has been done by comparing them against the pan-European reference E-OBS dataset (version 16.0). The 


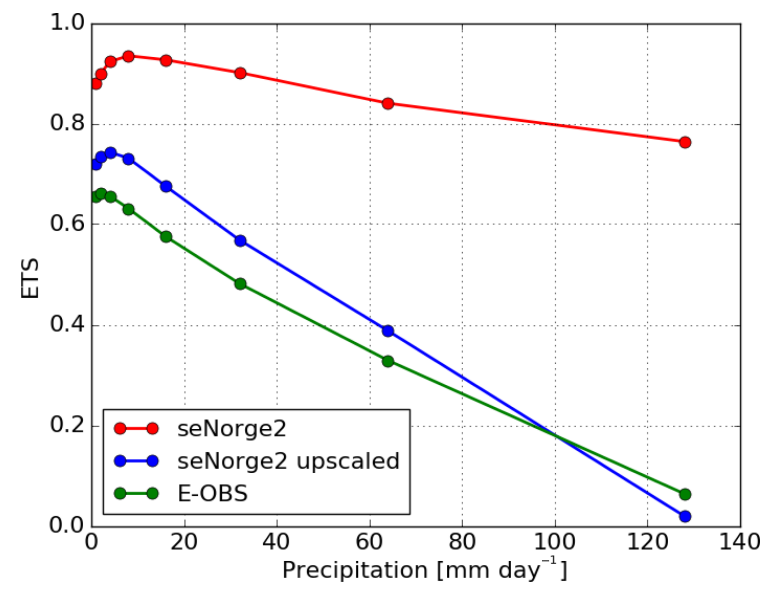

Figure 3. Equitable threat score (ETS) for daily precipitation over all the available Norwegian stations. Datasets are seNorge2 (red); seNorge 2 upscaled to the E-OBS grid (blue, $0.25^{\circ} \times 0.25^{\circ}$ geographical latitude-longitude coordinate reference system); and EOBS (green). Several precipitation thresholds have been considered: $1,2,4,8,16,32,64$ and $128 \mathrm{mmday}^{-1}$. Time interval: 30 years, from 1981 to 2010 .

dataset is compared on the E-OBS $0.25^{\circ}$ by $0.25^{\circ}$ regular latitude-longitude grid. Figure 4 shows the results regridded over the original seNorge 2 grid with a nearest-neighbor interpolation, such that the sizes of the boxes reflect the E-OBS grid resolution. As for Sect. 4.2, the 30-year period 1981-2010 has been considered in the verification, such that the statistics should be robust and resistant. E-OBS and seNorge 2 are based on different spatial interpolation methods, but they use the same observations. seNorge 2 makes use of more observations over Norway, in addition to the ECA\&D dataset that is the E-OBS archive of observations. As a consequence, the assessment of seNorge 2 presented in this section is relative to the E-OBS performances, rather than being in absolute terms.

In Fig. 4, the comparison between E-OBS and seNorge2 daily precipitation shows that the two datasets are rather similar over most of the domain. The fitted linear regression coefficient shows that for most grid points seNorge2 precipitation is within $\pm 20 \%$ of E-OBS precipitation and often very close to 1 . Note that in the work by Frei et al. (2003), the precipitation biases in a high-resolution gridded dataset over the Alps (underestimate) due to measurement biases and network biases (i.e., "distribution of rain gauges is biased, with high-elevation areas being undersampled in comparison to lowland and valley-floor conditions") is estimated to be within 5 and $25 \%$ (up to $40 \%$ in winter for elevations higher than $1500 \mathrm{~m}$ ). A multiplicative bias of up to $\pm 20 \%$ between seNorge 2 and E-OBS daily precipitation can be considered a satisfactory agreement between the dataset. The correlation coefficient is also above 0.9 for a large portion of the domain.

As highlighted by the boxplots in the two insets of Fig. 4, the significant differences between the two datasets are found (a)

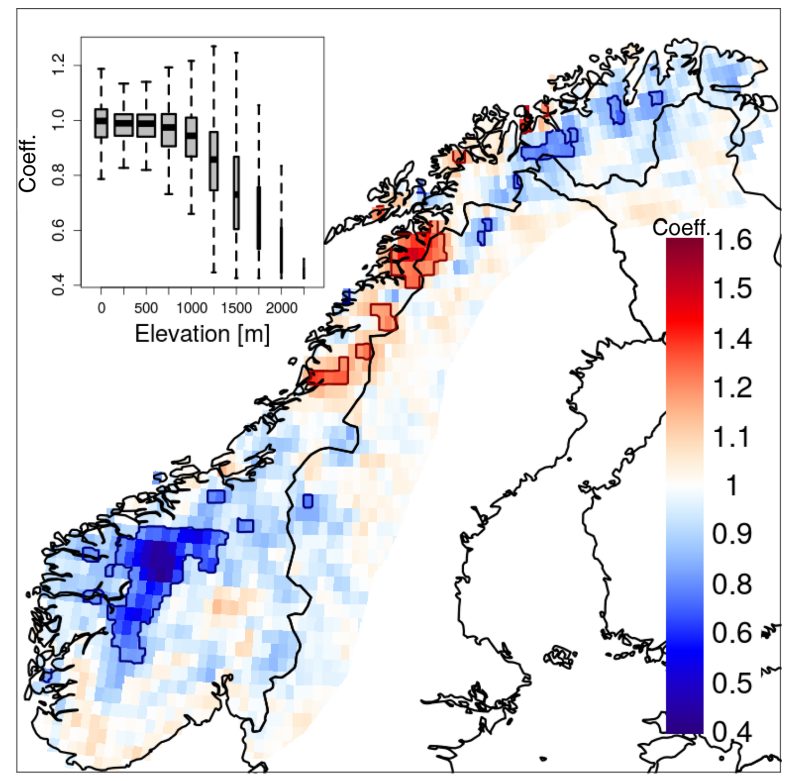

(b)

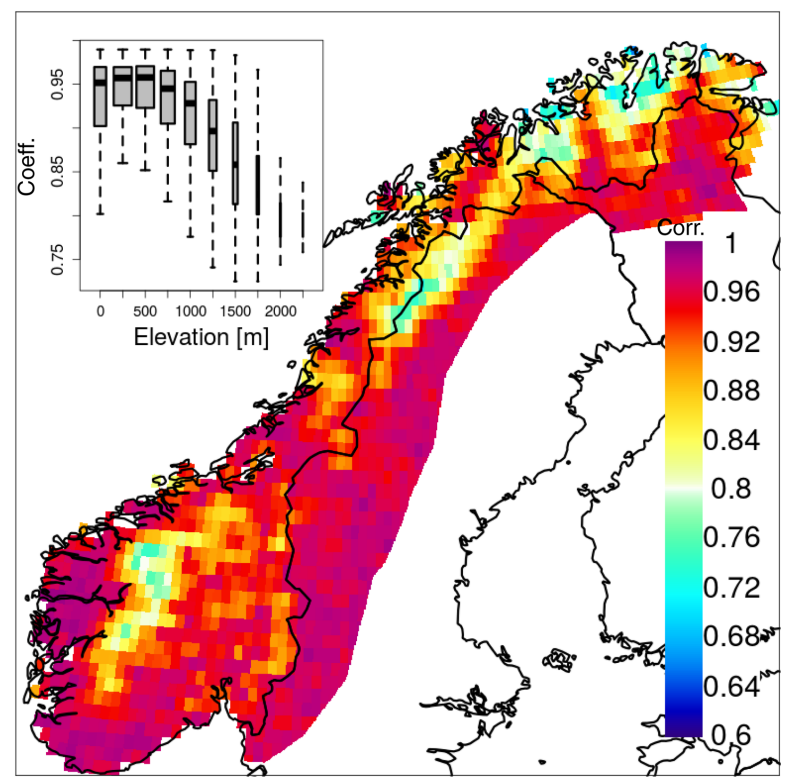

Figure 4. Daily precipitation comparison between E-OBS and seNorge2, which has been upscaled to the E-OBS grid $\left(0.25^{\circ} \times\right.$ $0.25^{\circ}$ geographical latitude-longitude coordinate reference system). (a) Fitted linear regression coefficient, seNorge $2=$ coeff . EOBS; regions where the coefficient values are smaller than 0.8 or larger than 1.2 are highlighted by thick contouring lines. (b) Correlation coefficient. The two insets in the top-left corners in the panels show the elevation dependence of the corresponding variable; note that the box width is proportional to the number of points in the elevation range.

in southern Norway; in the mountain area where the highest peaks are located, seNorge 2 underestimates precipitation compared to E-OBS. For elevation higher than $1000 \mathrm{~m}$, the linear regression coefficient gradually decreases, and it reaches the value of approximately 0.6 at $2000 \mathrm{~m}$. Anal- 
ogously, the correlation coefficients decrease to values of about 0.8 at $2000 \mathrm{~m}$. As an explanation, we have verified that in our interpolation method (Sect. 3.1), as $D^{h}$ becomes smaller and smaller, the optimization of $D^{z}$ also favors the smallest value of $500 \mathrm{~m}$, so that the adjustments at local scales involve a smaller number of grid points (i.e., in both the horizontal and vertical directions) than the ones for the larger spatial scales. By design, the interpolation scheme reconstructs local precipitation features only in the surroundings of station locations, where these features can be trusted, while in data-void areas the precipitation field is determined by the large-scale signal recovered by the available network of gauges. However, for those regions where the average difference between station elevations and topography is twice the $D^{z}$ value or more, elevation differences matter much more than differences in the horizontal distances. Given the raingauge network bias towards the lowest elevations (see Fig. 1), we may argue that the biases (underestimation) shown in Fig. 4 result from the fact that seNorge2 in the (almost) data-void areas of the mountains in southern Norway is representative of larger spatial scales than the ones recovered by E-OBS.

Note that Fig. 4 also shows a few grid points where seNorge 2 predictions significantly overestimate precipitation compared to E-OBS (red colors in the top panels) and the correlation reaches values between 0.7 and 0.8 . Most likely, these are the local effects of observations that have been included in seNorge 2 only, thus bringing valuable information on a local scale that is not present in E-OBS.

\section{Indirect evaluation of precipitation as a component of the water cycle}

\subsection{Comparison to hydrological observations}

In Fig. 5, the annual average catchment water balance is shown as the sum of runoff and actual evapotranspiration (i.e., sinks of water) against precipitation (i.e., input). The years from 2000 to 2013 have been considered and the 151 runoff measurements capture the outflow from catchments without artificial influence (e.g., hydropower) and glaciers. The actual evapotranspiration estimates were obtained from the MODIS Global Evapotranspiration Project (Mu et al., 2011).

The datasets considered in the comparison are (i) seNorge2 and (ii) seNorge1.1 (Mohr, 2008) (see the introduction). The regression lines are obtained through the application of a robust and resistant procedure as described in Lanzante (1996). seNorge1.1 shows higher annual total precipitation than the water losses for most catchments (coefficient of regression 1.08), while seNorge2 underestimates the input term in the water balance (coefficient of regression 0.63 ). The linear regressions between precipitation and the sum of runoff and evapotranspiration show a higher coefficient of determination $\left(r^{2}\right)$ for seNorge1.1 than

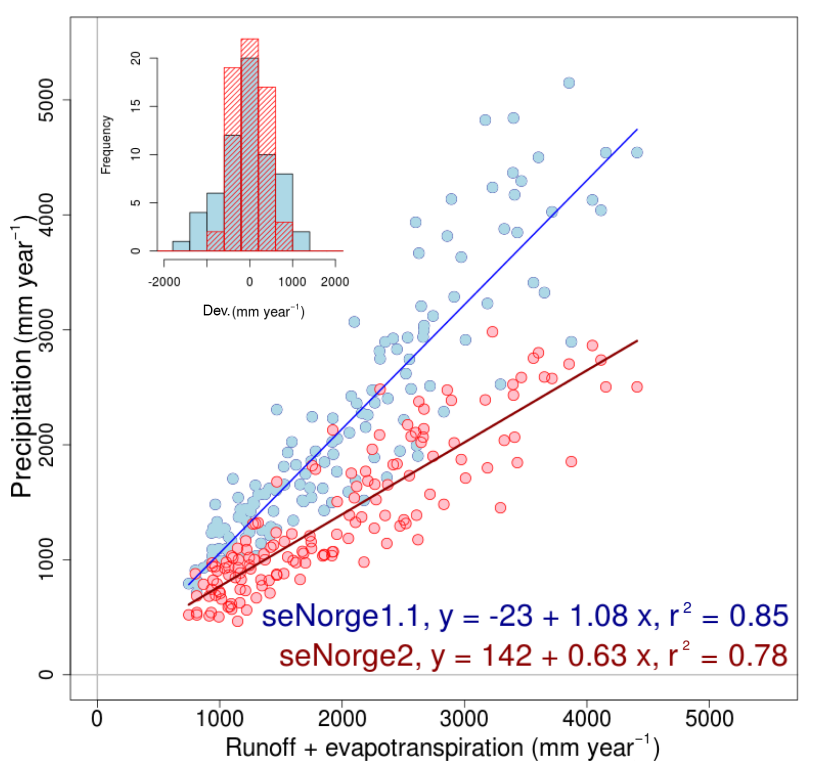

Figure 5. Average yearly precipitation (inputs of water to the catchment) against the sum of average yearly runoff and actual evapotranspiration (losses of water from the catchment) for the period from 1 January 2000 to 31 December 2013 for seNorge1.1 (blue) and seNorge 2 (red). The upper left box shows the distribution of regression residuals when the sum of runoff and actual evapotranspiration exceeds $2000 \mathrm{~mm} \mathrm{yr}^{-1}$.

seNorge2. On the other hand, the seNorge 2 points tend to lie closer to the regression line, as shown in the box on the upper left of Fig. 5 where the regression residuals are reported for both versions. The sum of squares of residuals (i.e., residual $=$ precipitation - predicted value by the linear regression) for seNorge 1.1 is twice as large as the one for seNorge2: $12958521.8\left(\mathrm{~mm} \mathrm{yr}^{-1}\right)^{2}$ for seNorge2 against $25435946.8\left(\mathrm{~mm} \mathrm{yr}^{-1}\right)^{2}$ for seNorge1.1. As a consequence, seNorge 2 provides less accurate (i.e., higher bias) but more precise (i.e., lower spread) estimates of the annual averaged precipitation than seNorge1.1.

\subsection{Impact on the seNorge snow model simulations}

Daily updated maps of snow conditions have been produced for Norway since 2004 by using the seNorge snow model (www.seNorge.no; Tveito et al., 2002; Engeset et al., 2004; Saloranta, 2012, 2014a, b, 2016) and the seNorge conventional climatological datasets as model forcing data. The simulated snow maps are used among others by the avalanche and flood forecasting services, hydropower energy situation analysis, as well as the general public.

Briefly described, the seNorge snow model (v.1.1.1) uses a threshold air temperature to separate between snow and rain precipitation, handles separately the ice and liquid water fractions of the total SWE, and keeps track of the accumulation and melting of snow. The daily snowmelt rate is a function of air temperature and solar radiation. The two 

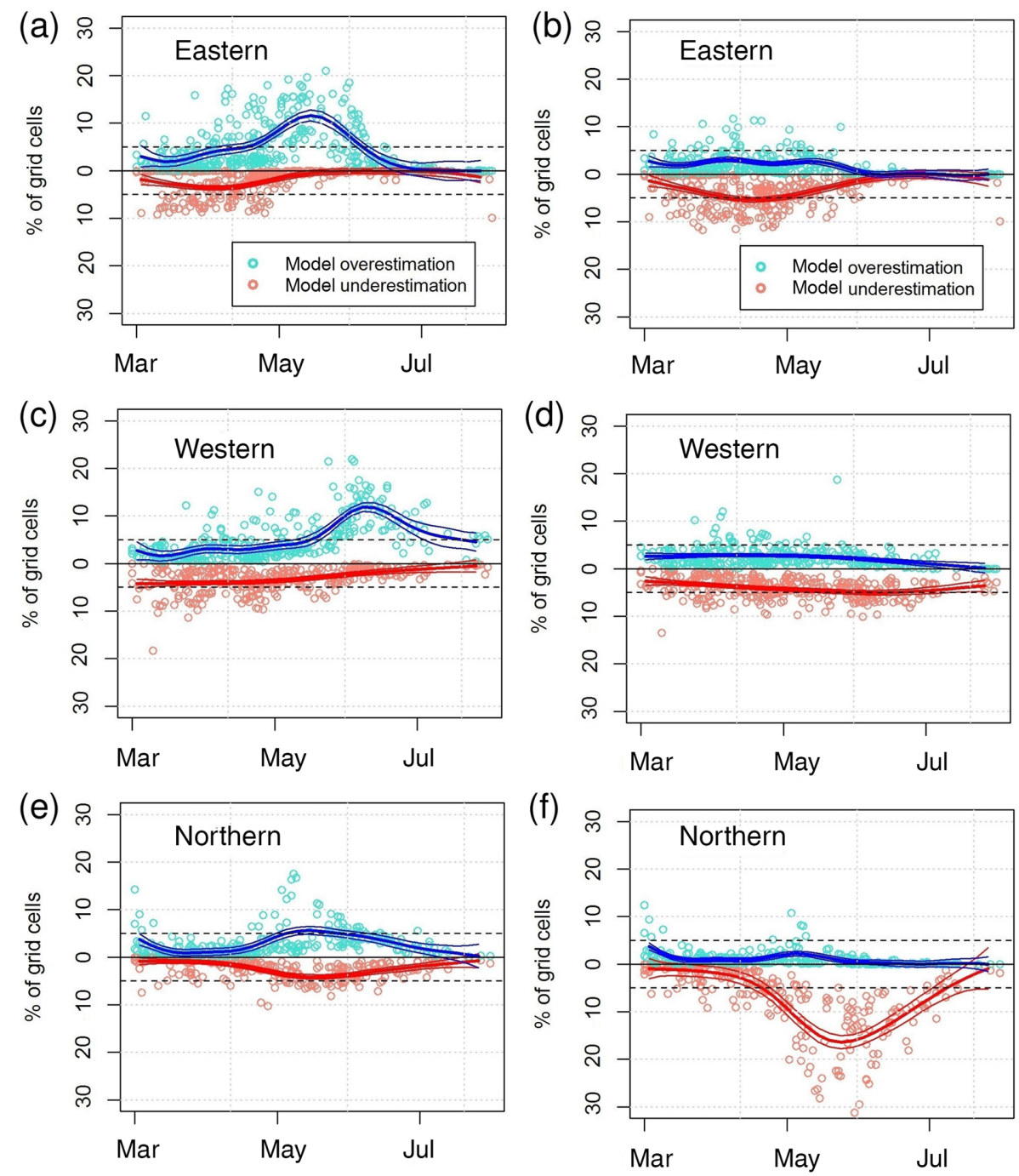

Figure 6. The model underestimation ( $F_{\mathrm{u}}$, red circles) and overestimation ( $F_{\mathrm{O}}$, blue circles) areas of SCA (\% of all grid cells) in the three regions (Fig. 7) and for the two grid data versions (v.1.1 in the left column and v.2 in the right column) in 2001-2015 (on the days when a MODIS satellite image is available for comparison). The solid lines denote GAM curves (with standard error) fitted to the cloud of points. The horizontal dashed lines denote the $5 \%$ deviation level within which the model results are considered "good" in NVE operational snow mapping (Saloranta, 2016).

melt model parameters are estimated using the extensive melt rate data from Norwegian snow pillows (Saloranta, 2014a). Moreover, the average grid cell snowmelt rates are also affected by the simulated fraction of snow-covered area (SCA) in the model grid cells.

In the evaluation, the seNorge snow model is run with the temperature and precipitation from the seNorge1.1 and seNorge 2 conventional climatological datasets as forcing in the period 2001-2015, and the simulated SCA values in the grid cells are compared to the corresponding SCA values derived from MODIS (MODerate resolution Imaging Spectroradiometer; http://modis.gsfc.nasa.gov/) satellite images using the Normalized Difference Snow Index (NDSI) and the Norwegian Linear Reflectance to snow cover algorithm
(NLR) (Salomonson and Appel, 2004; Solberg et al., 2006). No specific model calibration has been done prior to this evaluation. For each day when a satellite image is available, each grid cell is classified into three categories: model underestimation or overestimation, or good match. A good match is defined here as when the difference in the simulated and observed SCA does not exceed $\pm 50 \%$-points. These three categories are also assigned scores of $-1,0$ and +1 , respectively. This type of classification is applied in order to make the analysis more robust to systematic errors that can be present in the observed satellite-based SCA, e.g., due to the effect of forest canopy over the snow-covered area.

In order to make regional summaries of the evaluation results, Norway is divided into eastern, western and northern 

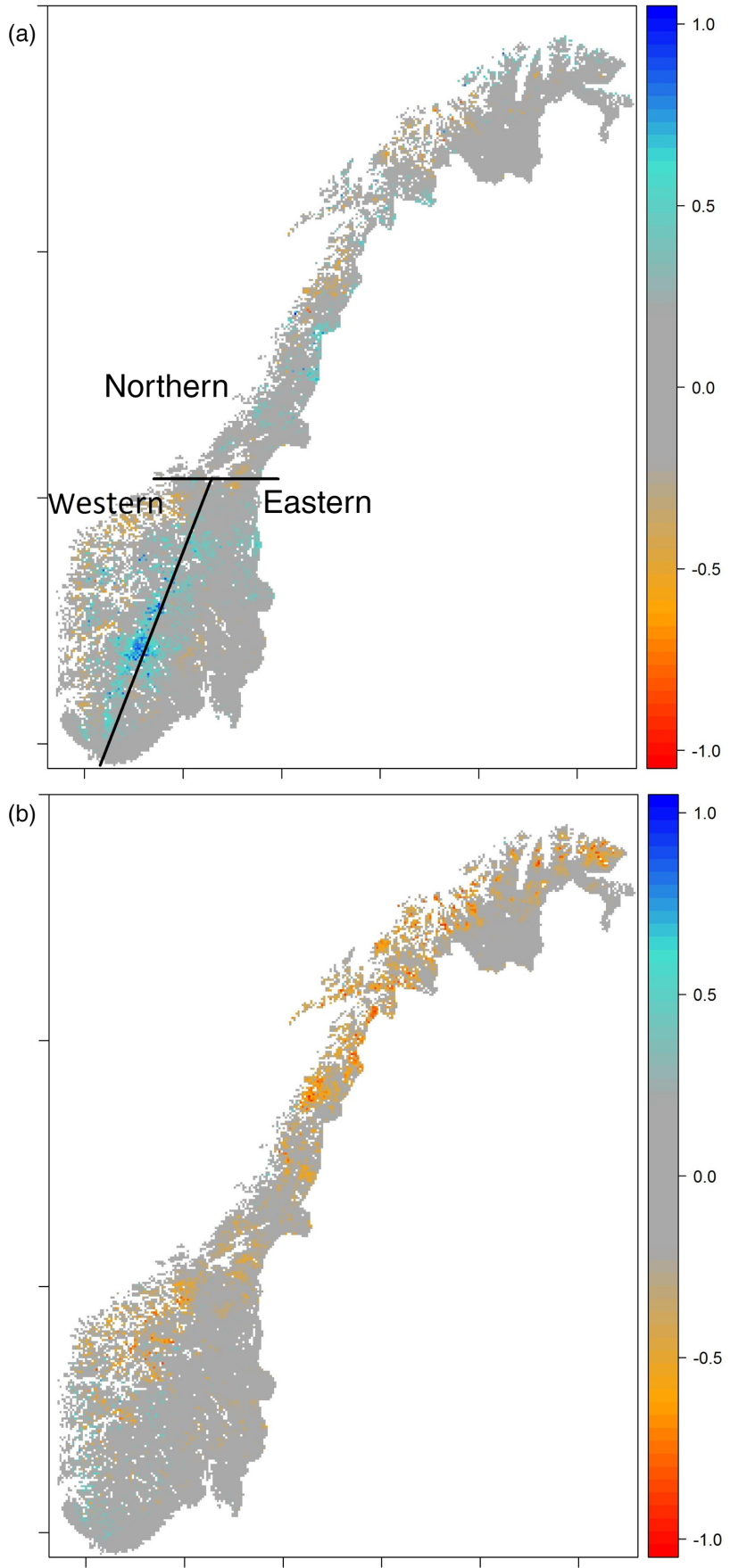

Figure 7. The bias index B for SCA in the seNorge grid cells for the two gridded dataset versions (v.1.1. in $\mathbf{a}$ and v. 2 in b) in March-July 2001-2015. In (a), the three regions used in Fig. 6 are shown.

regions and the fraction of the region's grid cells where the model simulations significantly underestimate $\left(F_{\mathrm{u}}\right)$ and overestimate $\left(F_{\mathrm{o}}\right)$ in comparison to the observed SCA (i.e., a deviation exceeding \pm 0.5$)$ are calculated for each day a satellite image is available.
Table 1. $90 \%$ percentile values of the model underestimation $\left(F_{\mathrm{u}}\right)$ and overestimation $\left(F_{\mathrm{O}}\right)$ (in \% of grid cells) in the three regions and for the two versions of the conventional climate dataset.

\begin{tabular}{lccc}
\hline $90 \%$ percentile $F_{\mathrm{u}}, F_{\mathrm{O}}$ & Eastern & Western & Northern \\
\hline seNorge 1.1 & $7 \%, 13 \%$ & $7 \%, 12 \%$ & $5 \%, 6 \%$ \\
seNorge2 & $8 \%, 4 \%$ & $7 \%, 5 \%$ & $18 \%, 3 \%$ \\
seNorge2 & $8 \%, 5 \%$ & $7 \%, 5 \%$ & $18 \%, 2 \%$ \\
\hline
\end{tabular}

* Based only on data from the Norwegian climate database, without using ECA\&D data outside Norway.

As the maximum deviation between observed and simulated SCA may occur at different times in different elevations and regions, a monthly mean of the model fit category scores $(-1,0,+1)$ is calculated for each seNorge grid cell and month (if at least 15 score values are available for the particular grid cell and month). Then, a bias index B is defined for each grid cell by summing up the minimum and the maximum values (i.e., the largest underestimations and overestimations) of the monthly mean scores (if at least three monthly means are available). This index B should reflect the systematic bias (if any) in simulated SCA in the particular grid cell encountered during the period from March to July.

The regional model underestimation and overestimation $\left(F_{\mathrm{u}}, F_{\mathrm{o}}\right)$ of the SCA, based on a total of 369,318 and 265 MODIS images in eastern, western and northern Norway, respectively, are shown in Fig. 6. The $90 \%$ percentile values of $F_{\mathrm{u}}$ and $F_{\mathrm{o}}$ are shown in Table 1 . These results show that the snow model run with seNorge1.1 data forcing clearly overestimates the SCA in the main melting season (May-June) in eastern and western Norway (Fig. 6). When the snow model is run with the seNorge 2 data forcing, the average $F_{\mathrm{u}}$ and $F_{\mathrm{o}}$ are roughly within a $5 \%$ deviation level for the whole analysis period from March to July in eastern and western Norway (Fig. 6). In northern Norway, however, the results show a different pattern, where the snow model run with seNorge1.1 data forcing performs rather well, while the model application based on seNorge2 data forcing significantly underestimates the SCA in May-June (Fig. 7; Table 1).

The maps of the bias index B (Fig. 7) reveal the patterns of SCA overestimation in eastern and western Norway when using seNorge 1.1 data, and of SCA underestimation in northern Norway when using seNorge 2 data.

\subsection{Impact on the DDD hydrological model simulations}

The DDD rainfall-runoff model (Skaugen and Onof, 2014; Skaugen and Mengistu, 2016) has been calibrated using the seNorge 2 meteorological grid over 136 Norwegian catchments (see Fig. 8). Input to the DDD model is only precipitation and temperature; the model is semi-distributed in that the moisture accounting (rainfall and snowmelt) is performed for 10 elevation zones of equal area. DDD has a two-dimensional 


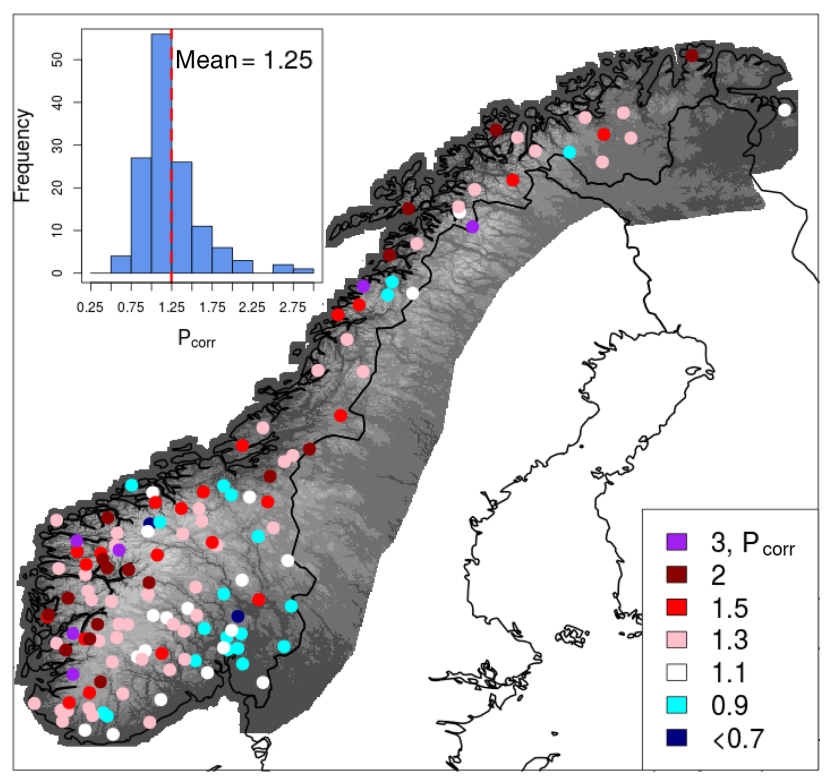

Figure 8. Geographical distribution of $P_{\text {corr }}$. The inset shows the histograms with the distribution of $P_{\text {corr }}$ values; the mean value is reported.

representation of the subsurface reservoir allowing for spatial variability of groundwater levels as a function of distance from the river network. Similar to the seNorge snow model, snowmelt is estimated using a calibrated temperature index model (without the additional solar radiation term) and a calibrated threshold temperature separating solid and liquid precipitation. The runoff dynamics of the DDD are characterized by a parsimonious parameter regime where the parameters are individually estimated from Geographical Information Systems (GIS) or from observed runoff records (recession analysis) and not collectively against observed runoff. Estimating the parameters in such a way reduces the tendency of model parameters when calibrated as a set, to collectively compensate for errors in input data and model structure, and hence acquire unrealistic values. DDD is calibrated by optimizing the Kling-Gupta efficiency (KGE) skill score (Kling et al., 2012) where the parameters are optimized so that correlation is maximized, variability is reproduced and bias is minimized.

The model parameters for the catchments have been calibrated for the period 1 September 2000 to 31 December 2014 and validated for the period 1 September 1985 to 31 August 2000. Then, in total, about 30 years of data are involved in the evaluation.

The mean KGE for the 136 catchments is 0.87 , and the mean bias is $0.1 \%$, indicating that the volume of observed and simulate runoff was practically the same. The ability in DDD to adjust the amount of precipitation obtained from the meteorological grids was crucial for obtaining such a low bias. The adjustment is made through a correction factor that linearly increases/decreases the precipitation in the course of the calibration. DDD has the ability to use different correction factors for precipitation as liquid (rain $P_{\text {corr }}$ ) or solid (snow $S_{\text {corr }}$ ).

The correction factor $S_{\text {corr }}$ should be higher than $P_{\text {corr }}$ due to the expected greater gauge undercatch for snow compared to liquid precipitation. However, for a calibrated parameter set, this is not always the case. For this study, the calibrated correction factors for precipitation and snow are meant to evaluate the seNorge2 dataset.

In general, the water balance seems reasonable, although the simulated actual evapotranspiration (AE) shows lower values when compared with the ones reported in Sect. 5.1, and it displays a rather high variability. Values of AE lower than the expected ones indicate that the correction factors are also too low, since the runoff volumes have reasonable values. So, with the understanding of a possible underestimation of AE, we interpret the calibrated corrections as indicators of underestimation/overestimation of precipitation in the seNorge 2 meteorological grid.

Figure 8 shows the calibrated $P_{\text {corr }}$ values plotted according to the centroid of the catchment they represent. The histograms of the calibrated $P_{\text {corr }}$ are also displayed. We see that the mean value for $P_{\text {corr }}(1.25)$ is well beyond 1.0. The geographical distribution of $P_{\text {corr }}$ reveals that seNorge 2 underestimates liquid precipitation on the western coast along the country and in the mountains. These results are consistent with the analysis of Sect. 4.3. $S_{\text {corr }}$ behaves rather similarly to $P_{\text {corr }}$, with a mean value of 1.18 .

\section{Data availability}

The seNorge2 dataset 1957-2015 is available at https://doi. org/10.5281/zenodo.845733. The observations of daily precipitation measured by the network of stations managed by the Norwegian Meteorological Institute can be downloaded at frost.met.no. Some of the agreements signed with the station data providers (i.e., other than the Norwegian Meteorological Institute) restrict the redistribution of the station data and they cannot be made freely available through frost.met.no. Please contact the corresponding author for further information.

\section{Conclusions}

The seNorge version 2.0 (seNorge2) high-resolution observational gridded dataset for daily total precipitation over Norway is described in this paper. The main objective of the dataset is to support climate and hydrology applications and is presented on a high-resolution grid with $1 \mathrm{~km}$ of grid spacing in both the zonal and meridional directions.

The MET observational network of raingauges is denser in the southern part of the domain and sparser in the north. The number of observations varies between 600 and 900, depending on the year. In addition, the distribution of observations 
has a bias towards the lower elevations and the highest densities are found locally along the coast. Most of the mountainous regions present a very sparse measurement network, especially for elevations above $1000 \mathrm{~m}$.

The climatological archive goes back to 1957 and is distributed in a single large file covering the time period 1957-2015, which is available for public download at http://doi.org/10.5281/zenodo.845733. Daily updates are stored and made available for public download at http://thredds.met.no/thredds/catalog/metusers/senorge2/ seNorge2/provisional_archive/PREC1d/gridded_dataset/ catalog.html. Furthermore, the data are shown on the web portals senorge.no and xgeo.no.

The spatial interpolation scheme relies on statistical (Bayesian) methods and is based on a combination of two classical interpolation schemes, namely optimal interpolation and successive-correction methods. An original multiscale-separation approach has been implemented by means of a statistical interpolation scheme where the information is passed through a cascade of (decreasing) spatial scales, which covers a wide range of scales from the synoptic motions down to the lower boundary of the mesoscale. seNorge 2 does not include the correction for undercatch due to the wind and the relation between precipitation and elevation is introduced only locally around the station locations. As a consequence, the predicted precipitation field may potentially underestimate the actual precipitation, especially at higher elevations where the station network is sparser.

The evaluation of the seNorge 2 daily precipitation fields is based on a 30-year dataset (1981-2010); the time period is long enough to provide useful information for extreme precipitation events too. The dataset of daily totals can properly represent both large-scale precipitation and small-scale features down to spatial scales of a few kilometers, depending on the network density. At station locations, the fraction of observed events that were correctly predicted is above 0.9 for precipitation intensities of about $10 \mathrm{mmday}^{-1}$, and it decreases to approximately 0.8 in the case of heavy precipitation (i.e., above $128 \mathrm{~mm}^{-1 a y}{ }^{-1}$ ). Intense precipitation is more likely to be underestimated than weak precipitation. seNorge 2 is especially well suited for those applications requiring a finer effective resolution of the predicted precipitation field, higher than the effective resolution of panEuropean datasets or global reanalysis. Over the grid points thus not necessarily corresponding to station locations, the quality of the seNorge 2 predicted precipitation is comparable to state-of-the-art pan-European datasets, though seNorge2 is expected to represent local scale features that cannot be included in coarser datasets. However, the uncertainties increase considerably for the data-void area on the mountains in southern Norway where seNorge 2 seems to significantly underestimate precipitation. The precipitation climatology derived from seNorge 2 provides reasonable results, though it is not the focus of this paper to evaluate the derived climatological fields.
The comparison of seNorge 2 with the measurements of the long-term water balance shows that seNorge 2 tends to underestimate precipitation. The indirect evaluations of seNorge 2 by considering the performances of the seNorge snow model and of the DDD model show that, for snow, a significant underestimation has been detected in northern Norway, while for the rest of the country the estimates are in reasonable agreement with the observations; for liquid precipitation, underestimation occurs along the western coast of Norway and in the mountains.

The seNorge project at MET has the objective of maintaining and improving the conventional (observational) climate gridded datasets of daily temperature and precipitation. $\mathrm{Fu}$ ture developments will focus on increasing the performances in data-sparse regions, e.g., following the recommendations of Masson and Frei (2014) on the use of climatological precipitation fields for the interpolation of daily precipitation. Furthermore, the issue of wind-induced underestimation of solid precipitation will be addressed.

Acknowledgements. Work at MET Norway and NVE on the activities presented in the article has been funded by Norwegian project "Felles aktiviteter NVE-MET tilknyttet nasjonal flom- og skredvarslingstjeneste" and NVE project "FoU-80200".

Edited by: David Carlson

Reviewed by: three anonymous referees

\section{References}

Aalto, J., Pirinen, P., and Jylhä, K.: New gridded daily climatology of Finland: Permutation-based uncertainty estimates and temporal trends in climate, J. Geophys. Res.-Atmos., 121, 3807-3823, 2016.

Barnes, S. L.: A technique for maximizing details in numerical map analysis, J. Appl. Meteorol., 3, 395-409, 1964.

Berg, P., Donnelly, C., and Rosberg, J.: HYPE EURO4M Evaluation Report, Tech. rep., UERRA Report 4.6, 2014.

Bergthörsson, P. and Döös, B. R.: Numerical weather map analysis, Tellus, 7, 329-340, 1955.

Bratseth, A.: Statistical Interpolation by means of successive corrections, Tellus A, 38, 439-447, 1986.

Crespi, A., Brunetti, M., Lentini, G., and Maugeri, M.: 1961-1990 high-resolution monthly precipitation climatologies for Italy, Int. J. Climatol., https://doi.org/10.1002/joc.5217, 2016.

Daley, R.: Atmospheric Data Analysis, Cambridge University Press, Cambridge, UK, 1991.

Eliassen, A.: Provisional report on calculation of spatial covariance and autocorrelation of the pressure field, Tech. Rep., Inst. Weather and Clim. Res., Acad. Sci., Oslo, 5, 1954.

Engeset, R., Tveito, O. E., Udnæs, H.-C., Alfnes, E., Mengistu, Z., Isaksen, K., and Førland, E. J.: Snow map validation for Norway, in: Proceedings XXIII Nordic Hydrological Conference 2004, 812 August 2004, Tallinn, Estonia, 8-12, 2004.

Erdin, R.: Combining rain gauge and radar measurements of a heavy precipitation event over Switzerland: comparison of geostatisti- 
cal methods and investigation of important influencing factors, $\mathrm{PhD}$ thesis, Bundesamt für Meteorologie und Klimatologie, MeteoSchweiz, Zurich, Switzerland, 2009.

Førland, E. and Tveito, O.: Temperatur og snødata for flomberegning, DNMI Report, The Norwegian Meteorological Institute, Oslo, Norway, 28, 51, 1997.

Frei, C., Christensen, J. H., Déqué, M., Jacob, D., Jones, R. G., and Vidale, P. L.: Daily precipitation statistics in regional climate models: Evaluation and intercomparison for the European Alps, J. Geophys. Res.-Atmos., 108, 4124, https://doi.org/10.1029/2002JD002287, 2003.

Gandin, L. S. and Hardin, R.: Objective analysis of meteorological fields, vol. 242, Israel program for scientific translations Jerusalem, 1965.

Gisnås, K., Etzelmüller, B., Lussana, C., Hjort, J., Sannel, A. B. K., Isaksen, K., Westermann, S., Kuhry, P., Christiansen, H. H., Frampton, A., and Åkerman, J.: Permafrost map for Norway, Sweden and Finland, Permafrost Periglac., 28, 359-378, 2017.

Haylock, M., Hofstra, N., Klein Tank, A., Klok, E., Jones, P., and New, M.: A European daily high-resolution gridded data set of surface temperature and precipitation for 1950-2006, J. Geophys. Res.-Atmos., 113, D20119, https://doi.org/10.1029/2008JD010201, 2008.

Hofstra, N., Haylock, M., New, M., Jones, P., and Frei, C.: Comparison of six methods for the interpolation of daily, European climate data, J. Geophys. Res.-Atmos., 113, D21110, https://doi.org/10.1029/2008JD010100, 2008.

Hofstra, N., New, M., and McSweeney, C.: The influence of interpolation and station network density on the distributions and trends of climate variables in gridded daily data, Clim. Dynam., 35, 841-858, 2010.

Ide, K., Courtier, P., Ghil, M., and Lorenc, A.: Unified notation for data assimilation: operational, sequential and variational, Practice, 75, 181-189, 1997.

Jazwinski, A. H.: Stochastic Processes and Filtering Theory, Courier Dover Publications, Mineola, New York, USA, 2007.

Jolliffe, I. T. and Stephenson, D. B.: Forecast Verification: A Practitioner's Guide in Atmospheric Science, John Wiley and Sons, : Chichester, UK, 2003.

Kalnay, E.: Atmospheric Modeling, Data Assimilation and Predictability, Cambridge University Press, Cambridge, UK, 2003.

Klein Tank, A., Wijngaard, J., Können, G., Böhm, R., Demarée, G., Gocheva, A., Mileta, M., Pashiardis, S., Hejkrlik, L., KernHansen, C., Heino, R., Bessemoulin, P., Müller-Westermeier, G., Tzanakou, M., Szalai, S., Pálsdóttir, T., Fitzgerald, D., Rubin, S., Capaldo, M., Maugeri, M., Leitass, A., Bukantis, A., Aberfeld, R., van Engelen, A. F. V., Forland, E., Mietus, M., Coelho, F., Mares, C., Razuvaev, V., Nieplova, E., Cegnar, T., Antonio López, J., Dahlström, B., Moberg, A., Kirchhofer, W., Ceylan, A., Pachaliuk, O., Alexander, L. V., and Petrovic, P.: Daily dataset of 20th-century surface air temperature and precipitation series for the European Climate Assessment, Int. J. Climatol., 22, 1441-1453, 2002.

Kling, H., Fuchs, M., and Paulin, M.: Runoff conditions in the upper Danube basin under an ensemble of climate change scenarios, J. Hydrol., 424, 264-277, 2012.

Kotlarski, S., Szabó, P., Herrera, S., Räty, O., Keuler, K., Soares, P. M., Cardoso, R. M., Bosshard, T., Pagé, C., Boberg, F., Gutiérrez, J. M., Isotta, F. A., Jaczewski, A.,
Kreienkamp, F., Liniger, M. A., Lussana, C., and PiankoKluczyńska, K.: Observational uncertainty and regional climate model evaluation: a pan-European perspective, Int. J. Climatol., https://doi.org/10.1002/joc.5249, 2017.

Lanzante, J. R.: Resistant, robust and non-parametric techniques for the analysis of climate data: theory and examples, including applications to historical radiosonde station data, Int. J. Climatol., 16, 1197-1226, 1996.

Lorenc, A.: Analysis methods for numerical weather prediction, Q. J. Roy. Meteor. Soc., 112, 1177-1194, 1986.

Lussana, C., Salvati, M. R., Pellegrini, U., and Uboldi, F.: Efficient high-resolution 3-D interpolation of meteorological variables for operational use, Adv. Sci. Res., 3, 105-112, https://doi.org/10.5194/asr-3-105-2009, 2009.

Lussana, C., Uboldi, F., and Salvati, M. R.: A spatial consistency test for surface observations from mesoscale meteorological networks, Q. J. Roy. Meteor. Soc., 136, 1075-1088, 2010.

Lussana, C., Tveito, O. E., and Uboldi, F.: seNorge v2.0: an observational gridded dataset of temperature for Norway, MET report 14-2016, publisher: the Norwegian meteorological Institute, Oslo, Norway, 2016.

Lussana, C., Tveito, O., and Uboldi, F.: Three-dimensional spatial interpolation of two-meter temperature over Norway, Q. J. Roy. Meteor. Soc., https://doi.org/10.1002/qj.3208, 2018.

Magnusson, J., Wever, N., Essery, R., Helbig, N., Winstral, A., and Jonas, T.: Evaluating snow models with varying process representations for hydrological applications, Water Resour. Res., 51, 2707-2723, 2015.

Masson, D. and Frei, C.: Spatial analysis of precipitation in a high-mountain region: exploring methods with multi-scale topographic predictors and circulation types, Hydrol. Earth Syst. Sci., 18, 4543-4563, https://doi.org/10.5194/hess-18-4543-2014, 2014.

Masson, D. and Frei, C.: Long-term variations and trends of mesoscale precipitation in the Alps: recalculation and update for 1901-2008, Int. J. Climatol., 36, 492-500, 2016.

Masson, V., Le Moigne, P., Martin, E., Faroux, S., Alias, A., Alkama, R., Belamari, S., Barbu, A., Boone, A., Bouyssel, F., Brousseau, P., Brun, E., Calvet, J.-C., Carrer, D., Decharme, B., Delire, C., Donier, S., Essaouini, K., Gibelin, A.-L., Giordani, H., Habets, F., Jidane, M., Kerdraon, G., Kourzeneva, E., Lafaysse, M., Lafont, S., Lebeaupin Brossier, C., Lemonsu, A., Mahfouf, J.-F., Marguinaud, P., Mokhtari, M., Morin, S., Pigeon, G., Salgado, R., Seity, Y., Taillefer, F., Tanguy, G., Tulet, P., Vincendon, B., Vionnet, V., and Voldoire, A.: The SURFEXv7.2 land and ocean surface platform for coupled or offline simulation of earth surface variables and fluxes, Geosci. Model Dev., 6, 929-960, https://doi.org/10.5194/gmd-6-929-2013, 2013.

Mohr, M.: New routines for gridding of temperature and precipitation observations for "seNorge. no", Met. no Report, 8, the Norwegian meteorological Institute, Oslo, Norway, 2008.

Mohr, M.: Comparison of versions 1.1 and 1.0 of gridded temperature and precipitation data for Norway, Norwegian Meteorological Institute, met no note, 19, the Norwegian meteorological Institute, Oslo, Norway, 2009.

Mu, Q., Zhao, M., and Running, S. W.: Improvements to a MODIS global terrestrial evapotranspiration algorithm, Remote Sens. Environ., 115, 1781-1800, 2011. 
Rocke, D. M. and Durbin, B.: Approximate variance-stabilizing transformations for gene-expression microarray data, Bioinformatics, 19, 966-972, 2003.

Salomonson, V. and Appel, I.: Estimating fractional snow cover from MODIS using the normalized difference snow index, Remote Sens. Environ., 89, 351-360, 2004.

Saloranta, T. M.: Simulating snow maps for Norway: description and statistical evaluation of the seNorge snow model, The Cryosphere, 6, 1323-1337, https://doi.org/10.5194/tc-6-13232012, 2012.

Saloranta, T.: New version (v. 1.1. 1) of the seNorge snow model and snow maps for Norway, Norwegian Water Resources and Energy Directorate, Norwegian Water Resources and Energy Directorate, Oslo, Norway, Rapport 6-2014, 2014a.

Saloranta, T. M.: Simulating more accurate snow maps for Norway with MCMC parameter estimation method, The Cryosphere Discuss., https://doi.org/10.5194/tcd-8-1973-2014, 2014b.

Saloranta, T. M.: Operational snow mapping with simplified data assimilation using the seNorge snow model, J. Hydrol., 538, 314 325,2016

Schiemann, R., Liniger, M. A., and Frei, C.: Reduced space optimal interpolation of daily rain gauge precipitation in Switzerland, J. Geophys. Res.-Atmos., 115, D14109 https://doi.org/10.1029/2009JD013047, 2010.

Simmons, A., Berrisford, P., Dee, D., Hersbach, H., Hirahara, S., and Thépaut, J.-N.: A reassessment of temperature variations and trends from global reanalyses and monthly surface climatological datasets, Q. J. Roy. Meteor. Soc., 143, 101-119, https://doi.org/10.1002/qj.2949, 2016.

Skaugen, T. and Mengistu, Z.: Estimating catchment-scale groundwater dynamics from recession analysis - enhanced constraining of hydrological models, Hydrol. Earth Syst. Sci., 20, 4963-4981, https://doi.org/10.5194/hess-20-4963-2016, 2016.

Skaugen, T. and Onof, C.: A rainfall-runoff model parameterized from GIS and runoff data, Hydrol. Process., 28, 4529-4542, 2014.
Solberg, R., Amlien, J., and Koren, H.: A review of optical snow cover algorithms, Tech. rep., Norwegian Computing Center Note, no, SAMBA/40/06, 2006.

Thompson, P. D.: Numerical Weather Analysis and Prediction, Macmillan, Oslo, Norway, 1961.

Thunis, P. and Bornstein, R.: Hierarchy of mesoscale flow assumptions and equations, J. Atmos. Sci., 53, 380-397, 1996.

Todini, E.: A Bayesian technique for conditioning radar precipitation estimates to rain-gauge measurements, Hydrol. Earth Syst. Sci., 5, 187-199, https://doi.org/10.5194/hess-5-187-2001, 2001.

Tveito, O., Førland, E., Dahlström, B., Elomaa, E., Frich, P., Hanssen-Bauer, I., Jónsson, T., Madsen, H., Perälä, J., Rissanen, P., and Vedin, H.: Nordic precipitation maps, DNMI Report, the Norwegian Meteorological Institute, Oslo, Norway, 22, 22, 1997.

Tveito, O. E., Udnæs, H.-C., Mengistu, Z., Engeset, R., and Førland, E. J.: New snow maps for Norway, in: Proceedings XXII Nordic Hydrological Conference 2002, Røros, Norway, 4-7 August 2002, 527-532, 2002.

Uboldi, F. and Buzzi, A.: Successive-correction methods applied to mesoscale meteorological analysis, Il Nuovo Cimento C, 17, 745-761, 1994.

Uboldi, F., Lussana, C., and Salvati, M.: Three-dimensional spatial interpolation of surface meteorological observations from highresolution local networks, Meteorol. Appl., 15, 331-345, 2008.

Wackernagel, H.: Multivariate Geostatistics: An Introduction with Applications, Springer Science and Business Media, New York, 2013.

Wahba, G. and Wendelberger, J.: Some new mathematical methods for variational objective analysis using splines and cross validation, Mon. Weather Rev., 108, 1122-1143, 1980. 